\title{
Correction to: When is it biological control? A framework of definitions, mechanisms, and classifications
}

\author{
Johan A. Stenberg ${ }^{1}\left(\mathbb{D} \cdot\right.$ Ingvar Sundh $^{2}\left(\mathbb{0} \cdot\right.$ Paul G. Becher $^{1}\left(\mathbb{D} \cdot\right.$ Christer Björkman $^{3} \cdot$ Mukesh Dubey $^{4}(\mathbb{D})$

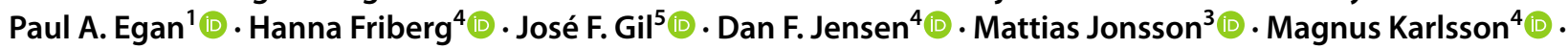

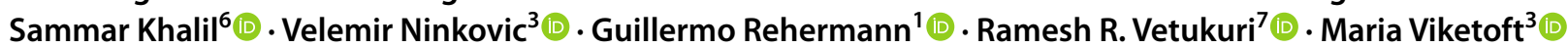

Published online: 11 May 2021

(c) Springer-Verlag GmbH Germany, part of Springer Nature 2021

\section{Correction to: Journal of Pest Science} https://doi.org/10.1007/s10340-021-01354-7

The original article contains an erroneous version of Fig. 2. The correct version of Fig. 2 is provided here.

The original article can be found online at https://doi.org/10.1007/ s10340-021-01354-7.

Johan A. Stenberg

johan.stenberg@slu.se

1 Department of Plant Protection Biology, Swedish University of Agricultural Sciences, Alnarp, Sweden

2 Department of Molecular Sciences, Swedish University of Agricultural Sciences, Uppsala, Sweden

3 Department of Ecology, Swedish University of Agricultural Sciences, Uppsala, Sweden

4 Department of Forest Mycology and Plant Pathology, Swedish University of Agricultural Sciences, Uppsala, Sweden

5 Department of Plant Biology, Swedish University of Agricultural Sciences, Uppsala, Sweden

6 Department of Biosystems and Technology, Swedish University of Agricultural Sciences, Alnarp, Sweden

7 Department of Plant Breeding, Swedish University of Agricultural Sciences, Alnarp, Sweden

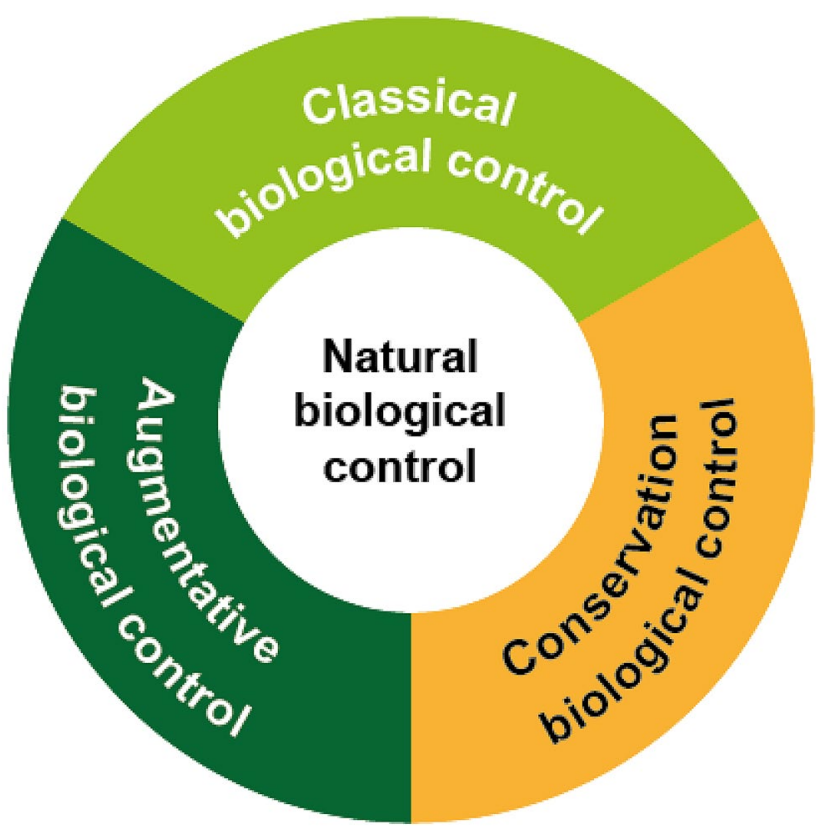

Fig. 2 The categories of biological control. Natural biological control denotes the ecosystem service carried out by resident natural enemies of pests and pathogens in the absence of human intervention. The other three categories typically depend on and interact with this baseline of control, to various degrees, hence its placement in the middle. Conservation biological control denotes the human stimulation of resident natural enemies to enhance their control of pests and pathogens. Augmentative biological control refers to human addition of mass-reared biocontrol agents, temporarily augmenting their population densities in a targeted area. Finally, classical biological control denotes human addition of new biocontrol agents for proliferation and long-term establishment. These three categories can be used individually or be combined (as indicated by the circle connecting each category with the other two)

Publisher's Note Springer Nature remains neutral with regard to jurisdictional claims in published maps and institutional affiliations. 